\title{
A patient with an aberrant pulmonary blood supply and recurrent infection
}

\author{
Radu Pescarus MD¹, George Rakovich MD², Denise Ouellette MD $^{2}$, Gilles Beauchamp MD²
}

R Pescarus, G Rakovich, D Ouellette, G Beauchamp. A patient with an aberrant pulmonary blood supply and recurrent infection Can Respir J 2010;17(4):e94-e95.

A case of intralobar pulmonary sequestration presenting with recurrent episodes of infection is reported. Pulmonary sequestration is a rare congenital malformation characterized by accessory lung tissue with no direct connection to the tracheobronchial tree and is supplied by an aberrant systemic artery. The aberrant artery is key to both diagnosis and treatment. The correct diagnosis may be suspected on clinical grounds and should be confirmed by identifying the lesion and aberrant artery on imaging studies. Surgical resection is curative, taking particular care not to injure the aberrant artery, which may result in devastating intraoperative hemorrhage.

Key Words: Congenital malformation; Lung; Pulmonary sequestration

$\mathrm{P}$ ulmonary sequestration is a rare congenital malformation, with an estimated incidence of $0.15 \%$ to $1.8 \%$ of the general population (1). It is classified as intralobar or extralobar based on anatomical characteristics (1-4). We report a case of intralobar pulmonary sequestration presenting with recurrent pulmonary infections.

\section{CASE PRESENTATION}

A 38-year-old woman was referred to the Hôpital MaisonneuveRosemont (Montreal, Quebec) for a right lower lobe mass. The patient initially presented with a seven-month history of productive cough, mild dyspnea and intermittent hemoptysis. She had previously been treated for pneumonia complicated by pulmonary abscess in the right lower lobe at 12 and 16 years of age. There was no family history of respiratory illness. Before referral, the patient had received several different courses of antibiotics over a two-month period without clinical improvement. She had no other symptoms, and a physical examination including pulmonary auscultation was normal. The results of standard blood tests were normal. A chest radiograph showed a cavitating mass below the right hilum. Bronchoscopy was normal. Computed tomography angiography revealed that the lesion, located within the posterior basal segment of the right lower lobe, was supplied by an aberrant systemic artery (Figure 1). Magnetic resonance angiography provided excellent anatomical detail of the aberrant artery where it originated from the abdominal aorta proximal to the celiac trunk; this confirmed the diagnosis of pulmonary sequestration (Figure 2). Venous drainage was effected normally through the inferior pulmonary vein.

Once the diagnostic workup was completed, the patient was taken to the operating room for surgical resection. The

\section{Patients présentant une irrigation sanguine pulmonaire aberrante avec infection récurrente}

\begin{abstract}
On signale ici un cas de séquestration pulmonaire intralobaire accompagnée d'épisodes récurrents d'infection. La séquestration pulmonaire est une rare malformation congénitale caractérisée par la présence d'une masse de tissu pulmonaire non fonctionnel sans lien direct avec l'arbre trachéobronchique et irriguée par une artère systémique aberrante. L'artère aberrante est la clé du diagnostic et du traitement. On peut soupçonner ce diagnostic sur des bases cliniques, mais il doit être confirmé par l'observation de la lésion et de l'artère aberrante aux épreuves d'imagerie. La résection chirurgicale est curative et se fait en veillant particulièrement à ne pas léser l'artère aberrante, pour ne pas risquer une hémorragie peropératoire catastrophique.
\end{abstract}

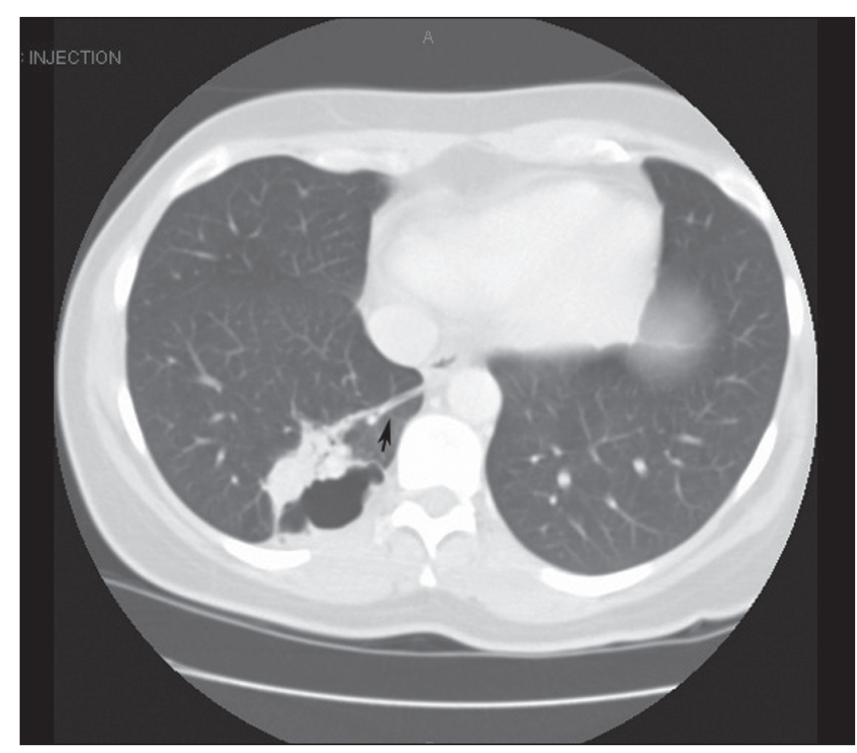

Figure 1) Computed tomography angiography showing a cavitating mass in the posterior basal segment of the right lower lobe. The lesion is supplied by an aberrant systemic artery (arrow)

approach was through a standard right posterolateral thoracotomy at the level of the fourth intercostal space. Following thorough lysis of the adhesions, the aberrant artery was isolated within the inferior pulmonary ligament and ligated. A right lower lobectomy was then performed in standard fashion when a sublobar resection appeared impossible due to extensive inflammatory changes. No other unexpected vascular anomalies were encountered. The patient was discharged seven days

${ }^{1}$ University of Montreal; ${ }^{2}$ Department of Surgery, Hôpital Maisonneuve-Rosemont, Montreal, Quebec

Correspondence: Dr George Rakovich, Department of Surgery, Hopital Maisonneuve-Rosemont, University of Montreal, 5415 boulevard de

l'Assomption, Montreal, Quebec H1T 2M4. Telephone 514-252-3400, e-mail george.rakovich@umontreal.ca 
after an uneventful postoperative course. Pathological analysis revealed a large cavitating lesion measuring $6 \mathrm{~cm} \times 10 \mathrm{~cm}$, consistent with intralobar pulmonary sequestration surrounded by fibrotic tissue.

\section{DISCUSSION}

Pulmonary sequestration is a rare congenital malformation that is believed to develop from an accessory lung bud $(1,2)$. The resulting mass of dysplastic lung tissue has no direct connection to the tracheobronchial tree and is supplied by an aberrant systemic artery $(1,3,4)$. There are two distinct types of sequestration: intralobar, in which the accessory lung tissue is incorporated within an otherwise normal lobe, and extralobar, in which the tissue is separate from the lung and has its own individual pleural covering (1-4).

Intralobar sequestration accounts for $75 \%$ of pulmonary sequestration cases (2). Although it may present at any age, it typically presents in older children or young adults with recurrent pulmonary infection or, less frequently, hemoptysis $(1,2)$. It involves the lower lobes in almost all cases, usually the medial and posterior basal segments, and occurs more frequently on the left side $(60 \%)(1-3)$. The aberrant artery usually originates from the descending thoracic aorta $(73 \%)$ and very rarely from the abdominal aorta (20\%). In contrast, extralobar sequestration usually becomes apparent in the newborn and is associated with diaphragmatic hernia and other congenital anomalies $(1,3,5)$. Characteristically, extralobar sequestration also has an abnormal systemic venous drainage (1).

The chest radiograph may suggest a diagnosis of intralobar sequestration if a mass in the medial or posterior basal segment is found in a young patient with chronic or recurrent localized infection (2). Most commonly, this will present as a wedgeshaped pleural-based opacity; however, complicated sequestra may present as a cavity containing an air-fluid level (1). Bronchoscopy is mandatory to rule out an endobronchial neoplasm, aspirated foreign body or extrinsic bronchial compression with secondary postobstructive pneumonitis. At this point, the differential diagnosis also includes lung abscess, cavitary neoplasm and bronchogenic cyst (2).

Definitive diagnosis relies on imaging studies and their ability to identify the aberrant artery. Computed tomography angiography is readily available and is diagnostic in $80 \%$ of cases $(2,5)$. Magnetic resonance angiography is especially useful for delineating the aberrant blood supply in ambiguous cases and may be important for optimal preoperative planning $(2,5)$.

Surgical resection is necessary because of the risk of recurrent infection and destruction of adjacent pulmonary parenchyma (3). The aberrant artery is often hidden by fibrosis; failure to identify it early in the course of the operative procedure may



Figure 2) Magnetic resonance angiography outlining the course of an aberrant systemic artery (black arrow) supplying a pulmonary sequestrum located in the right lower lobe. The artery originates from the abdominal aorta

result in inadvertent trauma and catastrophic hemorrhage (4). Because sequestration is a benign lesion, conservative resections should be favoured over anatomical lobectomy whenever possible (4). More recently, video-assisted thoracoscopic surgical techniques have also been used successfully (4).

\section{REFERENCES}

1. Corbett HJ, Humphrey GM. Pulmonary sequestration. Paediatr Respir Rev 2004;5:59-68.

2. Petersen G, Martin U, Singhal A, Criner GJ. Intralobar sequestration in the middle-aged and elderly adult: Recognition and radiographic evaluation. J Thorac Cardiovasc Surg 2003;126:2086-90.

3. Yucel O, Gurkok S, Gozubuyuk A, et al. Diagnosis and surgical treatment of pulmonary sequestration. Thorac Cardiovasc Surg 2008;56:154-7.

4. Kestenholz PB, Schneiter D, Hillinger S, Lardinois D, Weder W. Thoracoscopic treatment of pulmonary sequestration.

Eur J Cardiothorac Surg 2006;29:815-8.

5. Gezer S, Tastepe I, Sirmali M, et al. Pulmonary sequestration: A single-institutional series composed of 27 cases.

J Thorac Cardiovasc Surg 2007;133:955-9. 


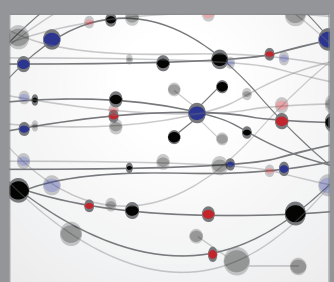

The Scientific World Journal


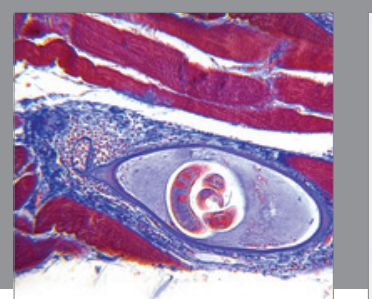

Gastroenterology Research and Practice

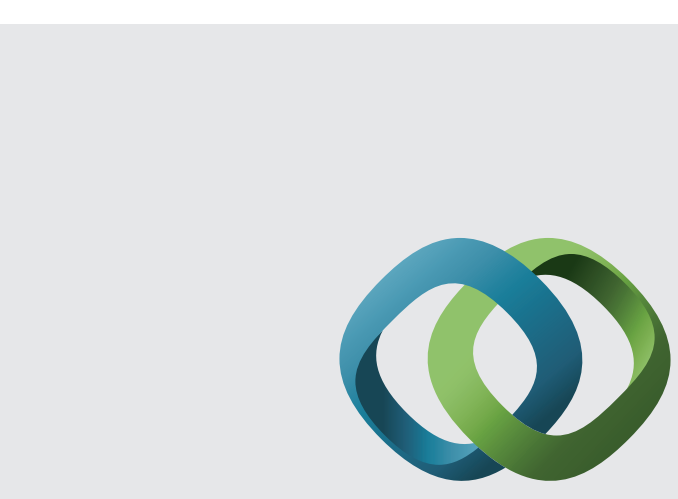

\section{Hindawi}

Submit your manuscripts at

http://www.hindawi.com
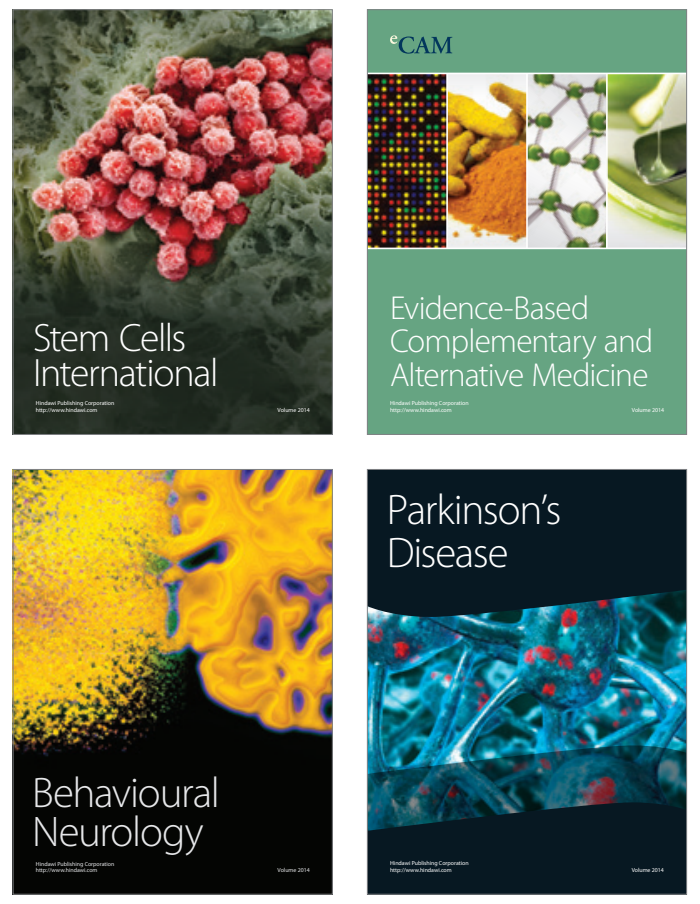
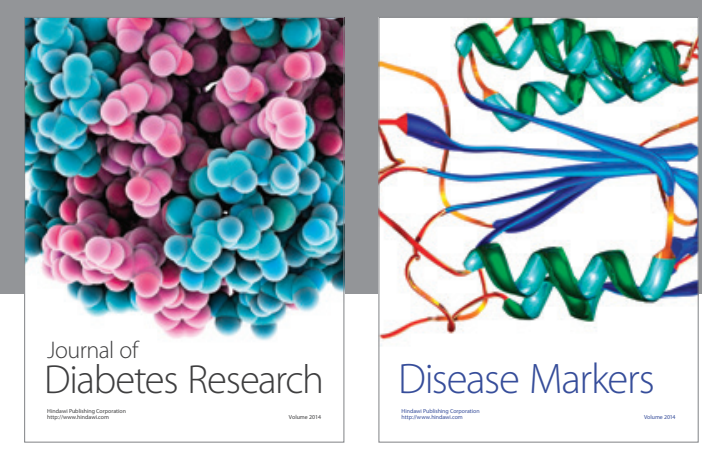

Disease Markers
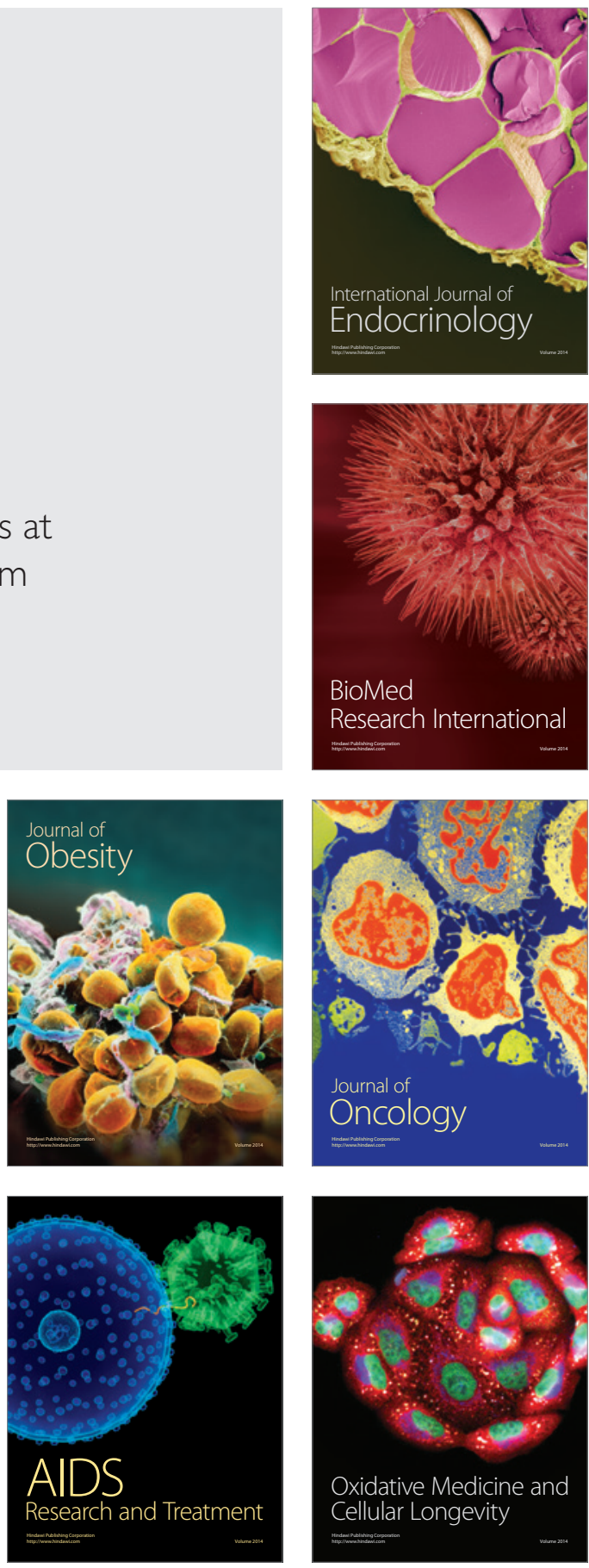